\title{
Prácticas participativas en el espacio barrial: su operatividad durante el peronismo
}

\section{Participative practices in the neighbourhood space: Its operativity under peronism}

\author{
Celia Cristina Basconzuelo \\ Universidad Nacional de Río Cuarto \\ Consejo Nacional de Investigaciones Científicas y Técnicas
}

(Argentina)

cbasconzuelo2003@yahoo.com.ar

\begin{abstract}
Resumen
Los diversos estudios historiográficos acerca del peronismo han revelado la riqueza de sus matices a escala local. En atención a ello, el objetivo de este artículo es analizar las prácticas participativas -en su modalidad asociativa y política- que se desplegaron en los barrios de una ciudad intermedia del sur cordobés, Río Cuarto, teniendo en cuenta las asociaciones vecinales por parte de la sociedad civil y las Unidades Básicas en tanto órganos del partido peronista. Se demostrará que la mediación de las demandas barriales fue un campo de disputa entre el fomentismo y las Unidades Básicas tal como en otras periferias urbanas del país se hubo registrado. Pero, a diferencia de esos centros, en las barriadas de esta ciudad del sur cordobés, los vecinos continuaron desarrollando prácticas sociales participativas por fuera y por dentro de las entidades fomentistas preexistentes; el peronismo no ocluyó la vida asociativa pero buscó controlarla y regularla jurídicamente, y si bien peronizó algunas comisiones de fomento no lo hizo con las asociaciones vecinales. Éstas, por su parte, registraron un proceso de renovación en los dos años terminales del peronismo.
\end{abstract}

Palabras Clave: Peronismo- Barrio - Unidades Básicas - Asociaciones Vecinales

BASCONZUELO, Celia Cristina, "Prácticas participativas en el espacio barrial: su operatividad durante el peronismo”, en Avances del Cesor, Año XI, No 11, segundo semestre 2014, pp. 59-75. 


\begin{abstract}
The diverse historiographical studies about Peronism have revealed certain richness of local-scale shades. Regarding to this, the objective of this article is to analyze the participative practices -both in its associative and political modalities- that took place in the neighborhoods of the city of Río Cuarto, Córdoba, taking into account both neighborhood associations and partisan Basic Units. It will be shown that the mediation of the neighbor demands became a disputed field between social-based foment and the Basic Units, just like is reported in other peripheral urbanizations. But in spite of this, in this city, neighbors kept developing associative practices both from inside and from outside of pre-existing foment entities; Peronism did not occlude the associative life but sought to control and regulate it. And even though it "peronized" some foment commissions, it did not the same with neighbor associations. These, instead, experienced a renovation process during the two final years of Peronism.
\end{abstract}

Key Words: Press - Rosario - Opinion - Interests - Governments and factions.

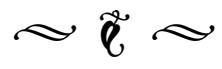

\section{Introducción}

La participación ciudadana en los espacios locales ha ganado terreno como objeto de estudio desde hace un par de décadas, y ese interés se ha visto reflejado en producciones contextualizadas en los procesos de afirmación democrática y de descentralización acaecidos a partir de los años ' 80.

La contemporaneidad de dicha cuestión no ha impedido, sin embargo, que su tratamiento pudiera remitirse a ciertas coyunturas históricas. Precisamente, esta inquietud ha motivado la elaboración del presente artículo que estudia las prácticas participativas durante los años peronistas en una escala local de análisis: los barrios de la ciudad de Río Cuarto, ubicada al sur de la provincia de Córdoba.

Infinidad de estudios han surcado la historiografía nacional proveyendo diversas claves interpretativas acerca del peronismo $\mathrm{y}$ en ese trayecto ha quedado claro, más allá de las posturas a veces encontradas, que las principales organizaciones identitarias - Partido y Movimiento - así como la relación Estado-Sociedad fueron atravesadas finamente por la construcción político-ideológica de rasgos populistas que sobrevino después de 1946. El rol del Estado, correspondiéndose con el modelo vigente de Estado Benefactor, profundizó su sesgo dirigista hacia una idea intervencionista con fuerte gravitación en la economía y en la sociedad; mientras el peronismo imprimía su sello particular al sistema político consagrando una conducción 
centralizada, movilizando las masas populares y concibiendo una imagen de la sociedad sin lucha de clases.

A su vez, esa forma de organización estatal buscó articular las provincias y poderes locales a un dispositivo nacional fundado en una identidad con pretensión unanimista, y a ello sirvieron diversos instrumentos: el Partido -constituido a nivel nacional en 1947-, las Unidades Básicas (en adelante UB) tanto masculinas como femeninas y otras pequeñas instituciones como los Centros Cívicos. Sin embargo, la reducción a la unidad partidaria no fue una tarea fácil, debido a las tensiones y conflictos latentes en las fuerzas locales; situación que ha sido puesta de relieve en varios estudios urbanos y rurales. ${ }^{1}$

La sociedad civil, por su parte, presentó una trama asociativa muy activa y densa a lo largo y ancho del país y un importante número de organizaciones surgidas en ese período se identificaron plenamente con la identidad peronista ${ }^{2}$, aunque hubo excepciones según lo muestran los estudios de caso. ${ }^{3}$

1. MACOR, Darío y TCACH, César, La invención del peronismo en el interior del país, Universidad Nacional del Litoral, Santa Fe, 2003. SALOMÓN, Alejandra, El peronismo en clave rural y local, Buenos Aires, 1945-1955, Universidad Nacional de Quilmes, Buenos Aires, 2012.

\section{DE PIERO, Sergio, Organizaciones de la sociedad} civil. Tensiones de una agenda en construcción, Paidós, Buenos Aires, 2005, p. 223; ROMERO, Luis Alberto, "E1 Estado y las corporaciones", en DI STÉFANO, Roberto, SÁBATO, Hilda y otros (compiladores) De las cofradías a las organizaciones de la sociedad civil. Historia de la iniciativa asociativa en Argentina. 1776- 1990, Gadis, Buenos Aires, 2002; SIDICARO, Ricardo, Los tres peronismos, Siglo veintiuno editores, Buenos Aires, 2002.

3. En Capital Federal algunas organizaciones mantuvieron su independencia civilista hasta 1954.

ACHA, Omar, Política y asociacionismo en los años
Los estudios historiográficos acerca de la vida asociativa vecinal y de la actividad de las UB a nivel local, son cada vez más prolíficos. En cuanto al fomentismo, si el objetivo es conocer su origen, los objetivos, la composición social, las actividades culturales y los vínculos con la política, varios trabajos pioneros centrados en el espacio bonaerense dieron cuenta de ello. Se trataba de un "asociacionismo de base" que alcanzó su madurez antes de la llegada del peronismo, pero cuando este fenómeno se instaló, habrían sido las UB quienes en realidad canalizaron las demandas sociales barriales hacia el Estado. Los estudios emprendidos acerca de la actividad fomentista en otras ciudades metropolitanas e intermedias del país han permitido reconocer líneas comunes y a la vez, matices singulares, en Córdoba y en Rosario, por ejemplo.

Respecto de las contribuciones acerca de las UB, han comprendido aspectos de su organización y dinámicas locales en Mar del Plata, Bahía Blanca y Córdoba que reflejaron la pugna de los representantes locales frente a las fuerzas disciplinarias y organicista que buscaban imponerse.

Las UB femeninas y el Partido Peronista Femenino también han merecido tratamiento histórico. Las investigaciones de Carolina Barry mostraron que existía una diferenciación en los roles, asignaciones y comportamientos políticos entre las UB masculinas y femeninas. Así, mientras las UB masculinas se asemejaron en su funcionamiento a las organizaciones partidarias previas al peronismo, las UB

terminales del peronismo clásicos ante la movilización católica (1954-1955). Disponible en: http://url.nuevomundo. revues.org [Consulta: 11 diciembre 2013]. 
femeninas constituyeron el organismo primario permanente, la célula base, el centro elemental de organización, adoctrinamiento, encargado de afiliar, adherir y capacitar a la mujer peronista.

En cuanto a los ensayos que abordaron simultáneamente fomentismo y peronismo, los resultados muestran como común denominador el fenómeno de la peronización extendido al asociativismo. En ciudades como Mar del Plata y Buenos Aires habría sido muy fuerte la ofensiva; en Bahía Blanca, un poco menos intensa ya que se constituyó una red de UB que actuó para captar las necesidades barriales.

El peronismo exhibió matices a escala local. En atención a ello, el objetivo de este artículo es analizar las prácticas participativas -en su modalidad asociativa y política- que se desplegaron en los barrios de una ciudad intermedia del sur cordobés, Río Cuarto, teniendo en cuenta las asociaciones vecinales por parte de la sociedad civil ${ }^{4}$ y las UB en tanto órganos del partido peronista. Ambas institucionalidades, si bien de naturaleza muy diferente, tenían como característica común su anclaje territorial en los barrios. Por lo tanto, su abordaje permitirá problematizar en la pequeña escala la relación entre la sociedad civil y el régimen político peronista a fin de responder a las cuestiones siguientes: ¿pudieron los vecinos experimentar prácticas asociativas de alcance vecinal con la misma intensidad que lo habían hecho en las décadas precedentes, cuando nació el fomentismo en Río Cuarto? Sus organizaciones de referencia,

4. El concepto empleado en este trabajo es de J. Cohen y A. Arato. COHEN, Jean y ARATO, Andrew, Sociedad civil y teoría politica, Fondo de Cultura Económica, México, 2000, pp. 8 y 10.

62 ¿pudieron actuar con cierta autonomía o bien, como se ha registrado en otros puntos del país, se vieron sometidas a un proceso de colonización peronista donde a su vez las UB cooptaron las demandas barriales?

Dicha preocupación es conducente de un análisis que demostrará que la mediación de las demandas barriales -en el caso de Río Cuarto- fue un campo de disputa entre el fomentismo y las UB tal como en otras periferias urbanas del país se hubo registrado. Pero, a diferencia de esos centros, en las barriadas de esta ciudad del sur cordobés, los vecinos continuaron desarrollando prácticas sociales participativas por fuera y por dentro de las entidades fomentistas preexistentes; el peronismo no ocluyó la vida asociativa pero buscó controlarla y regularla jurídicamente, buscó peronizar algunas entidades fomentistas, pero no pudo conseguirlo con las nuevas asociaciones vecinales. Estas, por su parte, registraron un proceso de renovación en los dos años terminales del peronismo, acentuando su gravitación tras la etapa de desperonización.

Desde el punto de vista metodológico se han seleccionado dos unidades de análisis: por un lado, las entidades asociativas vecinales en tanto organizaciones de la sociedad $\operatorname{civil}^{5}$ y por el otro, las UB en su carácter de entidades político-partidarias. A través de ellas se abordarán las modalidades de participación social, comunitaria y política y las prácticas concretas $^{6}$ que los vecinos ejercitaron en sus territorios de base, es decir, desde los barrios. Para ello, en la primera sección del trabajo se

5. El concepto pertenece a DE PIERO, Sergio, Organizaciones de la sociedad civil..., Op. Cit., p. 42.

6. Para el tratamiento de estos conceptos, ver CUNILL, Nuria, Laparticipación ciudadana, Centro Latinoamericano de Administración para el Desarrollo, Caracas, 1991. 
caracterizará la dinámica asociativa y política urbana. La segunda sección se explayará sobre las prácticas participativas distinguiendo tres momentos históricos. Un primer momento que se extendió cronológicamente hasta 1954, caracterizado por la coexistencia en el territorio barrial de las comisiones vecinales que ya venían trabajando desde el período anterior y las UB. El segundo momento se inició en 1954 cuando el asociativismo vecinal cobró nuevo impulso. Finalmente, el golpe militar de 1955 que derrocó al peronismo y desmontó las estructuras partidarias a nivel nacional y por ende local, marcó el final de las UB y el comienzo de una trayectoria de las vecinales ininterrumpida hasta la actualidad.

Respecto de las fuentes de información empleadas, por una parte se han consultado los tres diarios que circulaban en la ciudad durante la etapa de estudio, los cuales respondían a tendencias políticas confrontadas: El Pueblo, demócrata desde 1912, Justicia, que dejó atrás su afinidad radical desde 1921 y adhirió al peronismo, y La Calle que nació en 1954 siendo peronista. Precisamente, este rasgo de acentuada politización ha favorecido el contraste de información sobre todo acerca de las actividades de las $\mathrm{UB}$, reflejadas frecuentemente en $\mathrm{La}$ Calle, mientras las noticias vecinales ocupaban la atención de los otros dos. Por otra parte, se han considerado fuentes editas de la época, tales como Manual del Peronista y escritos del propio Perón. En cuanto a las fuentes inéditas se han empleado, por un lado, los expedientes del Concejo Deliberante donde quedaba registrado el tratamiento dado a los petitorios vecinales $y$, por el otro, las actas constitutivas de las asociaciones vecinales. Asimismo, se realizaron entrevistas con metodología semi- estructurada a los dos primeros fundadores de las asociaciones vecinales de Barrio Las Ferias y Santa Teodora. ${ }^{7}$

\section{La dinámica asociativa y política urbana}

En nuestros aportes previos hemos demostrado que conforme fueron loteándose los terrenos fiscales y urbanizándose la periferia de la ciudad de Río Cuarto (últimas dos décadas del siglo XIX y primeras del XX), se conformaron los núcleos barriales hacia el este y norte. Al poco tiempo, sus residentes comenzaron a peticionar ante el municipio para lograr mejoras y prácticamente, sin mediar más que un par de años, se organizaron las primeras entidades fomentistas. ${ }^{8}$ Entre los años ' 40 y ‘ 50 , Río Cuarto consolidó los rasgos de una ciudad intermedia y su perfil comercial. El censo de 1956 arrojaba la cifra de 62.582 habitantes. Se formaron nuevas barriadas como Fénix y Las Ferias en el sur, la profundización de la urbanización en Banda Norte hacia el norte de la ciudad, y Alberdi en el este. ${ }^{9}$ En el sector Quintas Oeste de la ciudad, antigua propiedad de la familia Cardarelli, comenzaba a formarse hacia fines de 1947 la futura Gran Villa Dálcar constituida con alrededor de

7. Carlos Ghiglione. Co-fundador de la Vecinal Las Ferias. Fecha de la Entrevista: 28/10/2005. Francisco Odierno. Fundador y primer Presidente de la Asociación Vecinal Santa Teodora. Co-fundador de la Federación de Asociaciones Vecinales. Fecha de la Entrevista: 9/12/2005.

8. BASCONZUELO, Celia, La experiencia del vecinalismo en Río Cuarto desde sus comienzos a la actualidad, Barchiessi Editora, Río Cuarto, 2005.

9. MAYOL LAFERRÈRE, Carlos, Historia de Rio Cuarto. Fascículo 7. Peronismo e intervención, Puntal, Río Cuarto, 1990, p. 10. 
doscientas quintas que comenzaron a ser loteadas.

Desde el punto de vista político, los años peronistas significaron la intervención permanente, asociada a la figura del Comisionado Municipal ${ }^{10}$; solo dos intendentes resultaron electos por comicios libres, Natalio Castagno (1952-1955) y Amadeo Dapena (1955), ambos peronistas.

El peronismo iba a desarrollar en Río Cuarto otro proceso que podía visualizarse en el espacio nacional: la construcción territorial de su política partidaria y ello se puso de manifiesto en dos aspectos. Por un lado, las pequeñas institucionalidades que se gestaban en el centro de la ciudad rápidamente se multiplicaban en los barrios. Así, una vez constituido el Partido Peronista a nivel nacional y en la provincia de Córdoba, se difundió reiteradamente a través de la prensa local la convocatoria para inscribirse. ${ }^{11}$ Este aspecto marcaba una gran diferencia con el Partido Radical así como también con el Socialismo, por cuanto ninguno de los dos consiguieron sostener sus comités y centros, respectivamente, en los barrios, excepto en tiempos de elecciones municipales o legislativas. ${ }^{12}$ Por otro lado,

10. Para un análisis de esta autoridad en otros contextos municipales, ver MARCILESE, José, "Estado provincial y municipios bonaerenses, una relación conflictiva en los años del primer peronismo", en Anuario del Instituto de Historia Argentina 'Dr. Ricardo Levene', Buenos Aires, 2009, No 9, pp.149-178. SALOMÓN, Alejandra, "Los comisionados municipales: figuras cooptativas del gobierno peronista bonaerense (1945-1948)", en Anuario de la Escuela de Historia Virtual, Buenos Aires, 2012, Año 3, No 3, pp. 154-174.

11. Justicia, Río Cuarto, 10/4/1947, p. 1; 25/4/1947, p. 1.

12. Por ejemplo, en las legislativas de 1948 los radicales organizaron sub comités en Barrio Industrial, Barrio Buena Vista, Barrio Brasca. Por amplia mayoría triunfó el 64 el amplio triunfo electoral que obtuvo el peronismo en las elecciones para presidente de $1951^{13}$, habilitó una apropiación simbólicoterritorial: Barrio Alberdi pasó a denominarse "General Juan Domingo Perón” y se pensó en un proyecto para que el Barrio Banda Norte fuese designado "Eva Perón".

Aparte del trabajo femenino que partía desde las UB, se constituyó en Río Cuarto un Centro Femenino de Acción Social, el 26 de octubre de 1947, orientado a fomentar la educación cívica, cultural y cristiana de la mujer, la agremiación de las afiliadas, defender la igualdad con el hombre en el ejercicio de sus derechos políticos y la protección de los niños. A mediados de noviembre consiguió tener sede propia, ya que hasta entonces las inscripciones se recibían en los domicilios de las mujeres participantes. Rápidamente, el Centro irradió su actividad hacia los barrios y el 6 de noviembre se organizó una subcomisión en Barrio Alberdi con una participación de sesenta adherentes. ${ }^{14}$ Simultáneamente, se había constituido el Centro de la Juventud Peronista, compuesto por "afiliados peronistas netamente identificados con el pensamiento del Sr. Presidente", con el objetivo de "organizar un movimiento de reafirmación y de

peronismo. De 4.172 votos frente a 2.732 votos radicales, obtuvo 755 votos en Barrio Alberdi y 581 votos en Banda Norte. Estos eran los dos circuitos electorales barriales, además del centro, en que estaba organizada la ciudad. El Pueblo, Río Cuarto, 28/2/1948, p. 6; 2/3/1948, p. 3; 18/3/1948, p. 2.

13. En los cómputos generales había cierta disparidad (votos peronistas fueron $16.803 \mathrm{y}$ radicales 12.240) pero computados por barrios se advertía la hegemonía: en Barrio Alberdi los votos peronistas sumaron 2.593 y los radicales 779; en Banda Norte 1.718 para el justicialismo y 880 para el radicalismo. Justicia, Río Cuarto, 12/11/1951, p. 1 .

14. Justicia, Río Cuarto, 27/10/1947, p. 1; 7/11/1947, p. 1. 
Unión partidaria y bregar por una democracia auténtica". Dicho Centro tuvo sus réplicas en el Centro 4 de junio, en Barrio Alberdi, y en el Centro Peronista en Banda Norte. ${ }^{15}$

En cuanto al plano asociativo, una intensa actividad encontraba a muchos ciudadanos de esta comarca compenetrados con la defensa de intereses e inquietudes diversas y reforzando su sociabilidad desde la horizontalidad de los vínculos. Había emprendimientos varios que registraban continuidad tales como las bibliotecas populares (Sarmiento y Mariano Moreno), las tradicionales sociedades de socorros mutuos, los clubes sociales y deportivos, agrupaciones de trabajadores (Sociedad Unión de Empleados de Comercio, Federación Obrera, Asociación de Maestros), entidades comerciales (Centro Comercial) y organizaciones agrarias (Sociedad Rural, Federación Agraria).

\section{Prácticas comparadas}

El momento de la coexistencia. La competencia por la apropiación del espacio barrial y la mediación de las demandas vecinales

\section{Vecinos movilizados y Comisiones Vecinales}

El emprendimiento de las principales obras públicas que se habían ejecutado en los barrios de la ciudad y la provisión de servicios, nacía en líneas generales de la iniciativa intendencial, según el modelo de municipio vigente. Sin embargo, nuestros estudios previos sobre el origen y desarrollo barriales evidenciaron que también los vecinos se habían movilizado

15. Ídem, 13/11/1947, p. 2. cada vez que necesitaron mejoras materiales o culturales. Esta pauta se ejercitó antes y después de 1913, cuando surgió la primera sociedad fomentista. Se aludió entonces a la presencia de una trayectoria histórica vecinal.

Desde ese momento hasta inclusive los años peronistas ¿cuál fue el repertorio de prácticas vecinales? Por un lado, la práctica peticionaria que evocaba el derecho constitucional. En los años '40 varias obras de infraestructura se concretaron por ese medio, tales como la extensión del alumbrado público en la periferia, el transporte urbano de pasajeros hacia los barrios, el requerimiento de agua corriente en sectores marginales, el pedido para que se instalara una escuela nocturna y se abriera una sala de primeros auxilios. ${ }^{16}$

Esta práctica no se vio interrumpida durante los años peronistas. Las gestiones para la provisión de algún servicio fueron encaradas por los propios vecinos que presentaban notas directamente al Comisionado Municipal o también ante la prensa local, probablemente ambas prácticas obedecieran al hecho de que las comisiones fomentistas existentes no ejercían una real representatividad. Así, un núcleo de vecinos de Barrio Alberdi elevó un petitorio solicitando la luz eléctrica y el agua corriente. Alrededor de setenta vecinos del barrio de la Plaza San Martín firmaron un petitorio contra los ruidos molestos nocturnos que acontecían en el sector. ${ }^{17} \mathrm{El}$ arreglo de las calles "del populoso barrio Alberdi", la instalación de un buzón de correo y de un foco de alumbrado público en Banda Norte, fueron iniciativas netamente vecinales relatadas por la propia

16. Justicia, Río Cuarto, 25/1/1943, p. 2; 3/3/1943, p. 1 ; 15/2/1943, p. 1

17. Ídem, 30/9/1948, p. 1;27/12/1951, p. 1 
prensa partidaria del peronismo. ${ }^{18}$ Vecinos de calle Saint Remy y Mitre (sector sudoeste de la ciudad) solicitaron la construcción de una plazoleta; los de barrio Pueblo Nuevo, en Banda Norte, lograron la apertura de una calle. ${ }^{19}$ En todos estos relatos no apareció la intervención de ninguna UB ni representante político.

Otra práctica frecuente fue el ejercicio del derecho a la palabra que consistía en difundir en la prensa local algunas de las solicitudes presentadas a la intendencia, o bien conseguir que las editoriales sentaran opinión sobre la situación de algunos barrios, explicitando qué obras debían ejecutarse, o bien cuáles otras que ya habían sido realizadas presentaban problemas en su funcionamiento. En este punto la palabra vecinal encontró un gran respaldo en las editoriales de los periódicos locales. Tratándose de una prensa politizada, esos comentarios respondieron muchas veces al interés político de sentar una crítica contra el gobierno de turno. ${ }^{20}$

Inclusive la propia prensa peronista no dudó en cuestionar los trabajos que urgía realizar en algunos barrios. Así, el diario $L a$ Calle, refiriéndose a la necesidad de agua y obras de cloacas en Banda Norte decía: "ha

18. La Calle, Río Cuarto, 12/3/1955, p. 2; 25/3/1954, p. 2

19. Archivo Histórico Municipal (en adelante AHM), Concejo Deliberante, Carpeta No XCLVI., Año 1953.

Exp. No XXXIX; año 1954. Exp. No XCLXVI.

20. Así, Justicia, en enero de 1947, trasladaba al comisionado municipal la preocupación de un grupo de vecinos del sector noreste de la ciudad por el mal estado de las calles y la presencia de sitios baldíos. En otro momento interpeló por la necesidad del servicio de transporte para "sectores bien poblados como Quintas del Oeste y Barrio Hipódromo" donde existían escuelas municipales. Justicia, Río Cuarto, 10/1/1947, p. 1; 25/6/1948, p. 1

66 llegado el momento de plantearlo con miras a una solución... El aporte del servicio sanitario a que nos referimos propenderá a una mayor población en ese hermoso barrio, y con ello al progreso y engrandecimiento de Río Cuarto".

En otro momento demandó la prestación del servicio de agua corriente de manera más eficiente "en barrios densamente poblados, donde debe buscarse la forma de solucionarlo". También requirió que se abriera una farmacia en Banda Norte y que se implementara la colocación de placas con los nombres de las calles en los barrios que carecían de ellas. ${ }^{21}$ Como se advierte, la palabra en la prensa favoreció el hecho de visibilizar los barrios en la opinión pública y ante el resto de la sociedad urbana, a la vez que interpeló al poder municipal aunque fuese peronista.

La institucionalización de una comisión fomentista constituía el ejercicio de la práctica asociativa y revelaba el alcance de los vínculos de sociabilidad construidos a tal fin. Ya se comentó que las primeras entidades de este tipo en Río Cuarto se constituyeron a partir de 1913 en los dos primeros barrios en formación: hacia el este de la ciudad (Barrio Alberdi) y hacia el norte (Banda Norte). Entre los años '30 y '40 se fortaleció el proceso, revitalizándose las ya existentes, mediante un proceso que significó refundar la antigua asociación; o bien como ocurrió en otros puntos de la ciudad, se crearon nuevas comisiones fomentistas. Así constatamos la creación de la Comisión de Fomento de Pueblo Alberdi (26-9-1937); la Comisión Vecinal de Fomento Banda Norte (19-8-1939), y una segunda en 1943. Asimismo, se registró la renovación de una

21. La Calle, Río Cuarto, 30/1/1954, p. 2; 8/12/1954, p. 2; 25/3/1954, p. $2 ; 16 / 2 / 1955$, p. 2. 
comisión directiva en Barrio Alberdi en 1947. De ésta se conoce que, una vez conocido el triunfo abrumador del peronismo en 1951 y en dicho barrio se plegó, junto con la comisión del municipio y las UB, para organizar un programa de festejos. ${ }^{22}$ Respecto de las restantes comisiones, las fuentes no permiten inferir una influencia del peronismo sobre ellas; las que por su parte ejercieron la práctica peticionaria, como por ejemplo, la vecinal de Banda Norte cursó una nota al municipio en 1947 demandando un mejor servicio de ómnibus. ${ }^{23}$

Este primer fomentismo siguió entonces el modelo prevaleciente en otras latitudes periféricas del país. En nuestra opinión coadyuvó a construir el espacio barrial mediante las prácticas sociales allí desplegadas ${ }^{24}$, lo cual implicó una forma de apropiación ${ }^{25}$ de ese territorio de base. Pero, además, vino a infundir una nueva identidad ${ }^{26}$ cuyos contenidos

22. Justicia, Río Cuarto, 22/11/1951, p. 1.

23. El Pueblo, Río Cuarto, 2/10/1947, p. 4.

24. La tesis que sostiene la capacidad transformadora de las acciones de los individuos o grupos sociales sobre el espacio, se encuentra desarrollada en los trabajos de los geógrafos Milton Santos y Jacques Lévy entre otros. SANTOS, Milton, La naturaleza del espacio, Ariel, Barcelona, 2000. LÉVY, Jacques, "Actores, objetos, entornos: inventar el espacio para leer el mundo", en LINDÓN, Alicia y Daniel HIERNAUX (directores) Los giros de la geografía humana. Desafíos y horizontes, Anthropos, Barcelona, 2010.

25. Se habla de "territorio apropiado", es decir, de creación de territorialidad, cuando los actores sociales, económicos y políticos procuran encontrar un lugar en el espacio y ello implica formas de control sobre las áreas. HAESBAERT, Rogério, $O$ mito da desterritorialização. Do fim dos territórios à multiterritorialidade, Bertrand Brasil, Río de Janeiro, 2011.

26. El concepto "identidad” se ha seguido de Manuel Castells. CASTELLS, Manuel, La era de la información. discursivos traslucían cada uno de los petitorios presentados. Esa identidad vecinal apelaba a las marcas tradicionales (condición de residente, propietario y contribuyente); la identificación con el barrio (explicitación de la pertenencia territorial); la apelación a valores como la laboriosidad y la honestidad, la búsqueda del progreso para fundamentar la demanda barrial. Sin embargo, la antigua identidad apartidaria fue soslayada por la adhesión al peronismo.

Entre 1948 y 1952 el movimiento vecinal se detuvo. Las fuentes inéditas pertinentes no permiten constatar la apertura de ninguna otra organización. La prensa que respondía a la militancia peronista ( $\mathrm{La}$ Calle) no registró actividades vecinales, en cambio focalizó en las prácticas sociales y culturales desarrolladas desde las UB.

\section{Las Unidades Básicas.}

El peronismo vino no solo a apropiarse de los espacios micro como parte de una estrategia más amplia de territorialización del poder $^{27}$, sino también a disputarlos ${ }^{28}$ y a ello

Economia, sociedad y cultura, V. II: "El poder de la identidad”, Alianza, Madrid, 1998, pp. 27-31.

27. Esta idea de territorializar el poder incluyó a los municipios. Mercedes Prol (2012) refirió la convocatoria que llevó a cabo el Consejo Nacional de Posguerra en marzo de 1945 cuando se realizó la primera reunión nacional de municipios y ello dio lugar a la creación de la Asociación de Municipios de la República Argentina, convertida en un eslabón más de la política de planificación estatal y de control hacia los espacios locales. PROL, Mercedes, Estado, movimiento y partido peronista. La ingeniería institucional en Santa Fe, 19431955, Siglo XXI editores, Buenos Aires, 2012, p. 67.

28. Las UB no fueron las únicas organizaciones peronistas actuantes a nivel barrial. También en Río Cuarto funcionaron los Centros Culturales. 
sirvieron las UB. En efecto, desde el punto de vista doctrinario fueron pensadas como "el organismo primario del partido" y sus atribuciones, estipuladas en la Carta Orgánica de 1947. Un año después, otra producción editada por el Consejo Superior del Partido, Manual del Peronista (1948), le dedicaba dos capítulos ratificando la organicidad primaria de la UB. ${ }^{29}$ Estas pequeñas instituciones actuantes desde los espacios de base eran, pues, funcionales a la estrategia de construcción de territorialidad peronista en el sentido de afiliar $\mathrm{y}$ adoctrinar.

El estudio de las UB en Río Cuarto reveló un repertorio amplificado de prácticas desarrolladas, tal como lo registrado en otras ciudades del país. En tal sentido, el ejercicio de la práctica política ponía en manos de las UB un recurso diferencial capaz de habilitar otras de gran impacto político: en tiempos electorales y cuando se conmemoraba el calendario peronista podían -y de hecho lo hicieron- movilizar al vecindario.

A modo de ejemplo, para la campaña electoral de $1954^{30}$, el Partido organizó los denominados "actos relámpagos" en las calles de distintos barrios, donde los candidatos -hombres y mujeres peronistas, acompañados por representantes de la CGT- dirigieron sus discursos fervorosos antelosvecinos convocados previamente por la prensa partidaria. En tres barrios -Brasca, Las Ferias y Paraná- se aludió al trabajo de las "colaboradoras de las unidades básicas barriales”, y otras mujeres que

29. PARTIDO PERONISTA, Manual del Peronista, Consejo Superior Ejecutivo, Buenos Aires, 1948, p. 184.

30. Cabe recordar fueron legislativas y para elección de vicepresidente ante el fallecimiento de Hortensio Quijano. venían de la UB de Barrio Presidente Perón. Los actos tuvieron como escenario la tribuna callejera, pero también los hubo en locales de las UB, como aconteció en la femenina de barrio Las Ferias. En otra de Barrio Presidente Perón pudo escucharse "la palabra del Líder por los altavoces de la agencia Mil". ${ }^{31}$ Una vez conocido el triunfo peronista hubo un trabajo de movilización desde las bases territoriales. Así lo relataba el diario partidario: "Desde hora temprana comenzaron a concentrarse en la Plaza Olmos delegaciones procedentes de las distintas unidades básicas de nuestra ciudad, incluyendo barrio Presidente Perón y Banda Norte portando banderas, estandartes $\mathrm{y}$ grandes cartelones, mientras en forma entusiasta vitoreaban al presidente de la Nación general Juan Perón, a la Jefa Espiritual de la Nación, Eva Perón, a las autoridades y al triunfo obtenido". Esa capacidad de movilización en manos de las UB también se veía en ocasión de los festejos por el día del trabajador. ${ }^{32}$

En síntesis, todas las posibles afinidades locales quedaban literalmente solapadas por las expresiones de correspondencia hacia las identidades políticas más caras al peronismo.

Un apartado especial merece el análisis sobre las UB femeninas en los barrios riocuartenses. Es conocido que la política inclusiva del peronismo se canalizó primero con la sanción del sufragio en 1947 y luego con la creación de la rama femenina del Partido, el 29 de julio de 1949. Dicha organización respondía a una lógica jerárquica, presidida por Eva Duarte y en orden siguiente, veintitrés

31. La Calle, Río Cuarto, $1 / 4 / 1954$, p. 3; 9/4/1954, p. 3; $12 / 4 / 1954$, p. $3 ; 3 / 4 / 1954$, p. $3 ; 10 / 3 / 1954$, p. 2.

32. Ídem, 28/4/1954, p. 2; 3/5/1954, p. 2 
delegadas censistas que supervisaban el trabajo de las subdelegadas, siendo éstas el cuadro directivo de las UB. Ninguna de ellas era elegida en forma directa sino designada por Eva Duarte. El Partido se reconocía íntimamente vinculado al movimiento peronista, aunque independiente de la rama masculina. Hacia 1951 existían 3.600 UB femeninas en todo el país que funcionaban como "canales de incorporación, de socialización y congregación de mujeres peronistas", como "centros de acción política" y no estuvieron solamente dedicadas a la instrucción y la asistencia social. ${ }^{33}$

Además, según se dijo, desde las UB femeninas se ejercitaban prácticas sociales. Prácticas que en principio correspondían a la Fundación Eva Perón y sin embargo, también desde las Básicas se hizo asistencia social. ${ }^{34} \mathrm{El}$ Centro Femenino, que ya se refirió, llevó a cabo en 1948 un reparto de víveres que favoreció a 2.000 familias en el cual colaboraron firmas industriales, comerciales y vecinos destacados. ${ }^{35}$ Por lo demás, el análisis periodístico permite afirmar que a partir de la instalación de las UB, las organizaciones que hasta ese momento habían asistido con ayudas materiales a las familias pobres de los barrios, se vieron prácticamente desplazadas. ${ }^{36}$

\section{BARRY, Carolina, Evita capitana. El Partido} Peronisrta Femenino 1949-1955, EDUNTREF, Buenos Aires, 2009, pp. 159 y 161.

34. Por ejemplo, la UB femenina que operaba en Barrio Pte. Perón, en setiembre de 1955 comunicaba que había llevado al domicilio del ciudadano Ernesto Altamirano la suma de $50 \$$ para gastos de remedios, ya que el mismo estaba imposibilitado de trabajar por su enfermedad. $L a$ Calle, Río Cuarto, 8/9/1955, p. 3

35. Justicia, Río Cuarto, 26/1948, p. 1.

36. Entre los años 1943 y 1946 suele mencionarse la tarea asistencial de instituciones localizadas dentro y fuera de los barrios, tales como la Sociedad de Beneficencia,
Por otra parte, las UB sirvieron a la reproducción de prácticas simbólicas que al peronismo le interesaba recrear a través de su liturgia propia. Además del Día el Trabajador y del Día de la Lealtad, una fecha particular era la conmemoración del Renunciamiento. En la ocasión se movilizaban las UB femeninas. La prensa partidaria relataba el rol de delegadas censistas como oradoras principales, acompañadas por las afiliadas y las alumnas de los cursos de capacitación. Asimismo, acompañaba el trabajo barrial, representando así otra práctica tributaria de una estrategia de posicionamiento en la opinión urbana. Desde las páginas del diario afín, La Calle, solía convocarse a los afiliados y también a los vecinos para que asistieran a las clases doctrinarias que se dictaban diariamente en la UB del Barrio Presidente Perón. Las columnas periodísticas difundían cada acción política emprendida por las UB, las actividades culturales y todos los comunicados que a las delegadas y subdelegadas censistas les interesaba difundir.

Pero, también iba a desarrollarse una prensa procedente de las propias UB. En junio de 1955 se anunciaba la aparición en la ciudad del periódico del Partido Peronista Femenino Conquista, editado en la Capital Federal. El órgano era concebido como "un punto de unión entre las Unidades Básicas de todo el país" ${ }^{37} \mathrm{La}$ iniciativa implicaba explayar una práctica política de vuelo territorial que significaba articular el conocimiento sobre el

la Comisión femenina de la Pía Unión de San Antonio de Padua, el Club Sportivo y Cultural Alberdi y las cooperadoras de escuelas municipales. Justicia, Río Cuarto, 1943-1944.

37. La Calle, Río Cuarto, 3/6/1955, p. 3. 
conjunto de las UB del país, y desde el punto de vista local ir a la búsqueda del público vecinal, femenino, para disputar su formación cultural. Con esa iniciativa se competía a nivel barrial en la captación del público ya que las entidades fomentistas primero, $y$ sobre todo las asociaciones vecinales después, emprendieron la tarea de editar folletos para divulgar las acciones emprendidas por la dirigencia barrial en áreas que consideraban de interés colectivo.

El proceso de consolidar identidad política devino asimismo del ejercicio de las prácticas culturales, en donde también intervinieron las UB.En este punto iban ala búsqueda delavecina principalmente para disputar su formación y capacitación. Mujeres profesionales dictaban los cursos y la propia subdelegada censista se encargaba de difundirlos a través de la prensa partidaria. Así, la UB del partido peronista con sede en Barrio Presidente. Perón, comunicaba "a sus afiliados y público en general" que se reanudaban las clases de corte y confección, de lencería, tejidos, arte culinario y preparación de alumnos primarios. Otra UB, actuante en Barrio Banda Norte también anunciaba que se dictaban clases de corte y confección, labores, danzas nativas y capacitación escolar. La misma actividad se registraba en la UB del Barrio Las Ferias, ubicado al sur de la ciudad. También se dictaban clases gratuitas a los niños de cualquier establecimiento que hubieran sido aplazados en los cursos escolares y tuviesen que ser preparados para los exámenes complementarios. Por otra parte, el comienzo y la culminación de un año escolar era ocasión para un festival convocante casi siempre de "un gran público asistente", donde la subdelegada aprovechaba para ensalzar a través de su discurso la obra del "Líder" y el recuerdo de Eva Perón, y de esta manera -junto a los cánticos peronistas- se lograba articular ese pequeño colectivo barrial a las matrices de la identidad política peronista. ${ }^{38}$

Otro campo de competencia que ocuparon las UB fue la promoción de la sociabilidad intrabarrial. En ellas se organizaban bailes en distintos momentos del año y especialmente en carnaval que convocaban al conjunto de los vecinos, a las familias, alentados por la presencia de conjuntos orquestales que allí actuaban.

No obstante, este amplio abanico de prácticas ejercitadas, no se ha podido constatar en el caso riocuartense que las UB mediaran por las demandas materiales del barrio; si alguna de ellas hubiese presentado un proyecto, éste habría quedado registrado en los expedientes del Concejo Deliberante, hecho que no ocurrió. Sí, en cambio, se explayaron en el campo cultural barrial. Además de los señalado en el párrafo anterior, desde las UB se dictaban conferencias que abordaban temas de formación ciudadana ${ }^{39}$ y se abrieron bibliotecas, como en Barrio Presidente Perón. ${ }^{40}$ Así, lograron disputarle al primer fomentismo un campo de acción que lo había caracterizado.

38. Ídem, 3/5/1954, p. 1; 2/6/1954, p. 3; 31/3/1955, p. 5. 39. Ídem, 21/5/1954, p. 3; 2/6/1954, p. 3; 10/12/1954, p. $3 ; 31 / 3 / 1955$, p. $5 ; 18 / 5 / 1955$, p. 3.

40. En dicho barrio se constituyó en mayo de 1955 el Centro y Biblioteca 17 de octubre, entidad anexa a la UB. Ídem, 18/5/1955, p. 3. 
La renovación del vecinalismo en tiempos del peronismo

Entre 1953 y 1954 tuvieron lugar dos decisiones de importancia para la vida de las organizaciones vecinales en un caso y de las UB en el otro. El gobierno local conducido por el peronista Natalio Castagno emprendió en 1953 la decisión de regular mediante ordenanza las organizaciones vecinales. ${ }^{41}$ Una normativa muy similar regía en otras ciudades. ${ }^{42}$ Aquí se les otorgaba el carácter de "delegaciones municipales honoríficas"; a las cuales se trasladaba el ejercicio de algunas competencias mientras el departamento ejecutivo municipal, concebido como órgano superior de gobierno, retenía la titularidad de las mismas. Creaba una subalternidad política de esas organizaciones en varios sentidos: instituía la figura del Delegado Municipal ante quien las comisiones debían presentar todas las solicitudes de mejoras barriales; sujetaba los mandatos de las comisiones al período correspondiente al intendente municipal y dejaba a criterio del ejecutivo y Concejo Deliberante local, la aprobación de cada constitución vecinal. La ordenanza introducía pautas para ordenar también ciertos aspectos de la vida asociativa ${ }^{43}$, además regulaba los

41. Archivo Histórico Municipal de Río Cuarto. Concejo Deliberante. Año 1953. Ordenanza sobre Comisiones Vecinales. 16/10/1953.

42. En Bahía Blanca el municipio dictó una ordenanza en 1948 que regulaba la organización de las sociedades de fomento. MARCILESE, José, “ La sociedad civil y el primer peronismo. El fomentismo de Bahía Blanca y su lugar dentro de la "comunidad organizada", en Nuevos Mundos Mundo Nuevo, París, 2009.

43. En tal sentido, estipulaba la celebración de una asamblea general y anual en cuyo desarrollo los socios discutían y aprobaban las memorias y balances. Preveía la formación de una comisión directiva integrada por cinco miembros y direccionaba la composición de las vínculos intervecinales ${ }^{44}$ y prohibía toda injerencia en cuestiones políticas, raciales o religiosas.

En síntesis, queda claro que el peronismo no iba a ocluir la participación comunitaria pero había resuelto controlar ese proceso social en la escala local. ¿Cómo explicarlo? Una respuesta podría hallarse en la visión que el propio Perón tenía de la sociedad civil y que el intendente peronista -Natalio Castagno- sin duda conocía. Algunos textos como La Comunidad Organizada ${ }^{45}$, Apuntes de Organización Peronista ${ }^{46}$, Apuntes de Sociología Peronista $^{47}$ y Conducción Politica ${ }^{48}$, reflejaban

representaciones vecinales con un criterio selectivo: "la comisión directiva de las Comisiones Vecinales se constituirán con los miembros que establezcan los estatutos respectivos y deberán ser residentes del lugar, propietarios, comerciantes o personas que ejerzan una profesión liberal" (art. $2^{\circ}$ ).

44. Se disponía que cada dos años tuviese lugar un congreso de comisiones vecinales en un local designado por el ejecutivo local y con el auspicio municipal; la presidencia de dicha reunión se reservaba al intendente municipal o un delegado suyo.

45. Perón, Juan Domingo. La Comunidad Organizada. Disponible en: http://www. www.jdperon.gov.ar/ institucional/cuadernos/Cuadernillo6.pdf [Consulta: 15 octubre 2013].

46. Estos apuntes fueron en realidad clases dictadas por Perón en la Escuela Superior Peronista. La institución nació por decreto el 4 de diciembre de 1950 y tenía como objetivo formar intelectual y moralmente a los dirigentes del Partido Peronista. Escuela Superior Peronista. Apuntes de organización peronista. Disponible en: http://www. movimientoperonista.com/biblioteca.html [Consulta: 1 junio 2013].

47. Escuela Superior Peronista. Apuntes de Sociología peronista. Disponible en: http://www. archivoperonista. com/.../apuntes/.../apuntes-sociologia-peronista-escuela. [Consulta: 20 diciembre 2013].

48. El texto resultó de una recopilación de clases dictadas también en la Escuela Superior Peronista. En dicho libro 
claramente los principios centrales sobre los cuales debían asentarse las relaciones sociales, de manera que no quedasen libradas a la acción espontánea. Las organizaciones de la sociedad civil y las UB serían alcanzadas por esa lógica.

En1953,comoefectosindudaalaordenanza municipal que habilitaba la formación de comisiones vecinales, el bloque peronista del Concejo Deliberante solicitaba se diera tratamiento al pedido de reconocimiento de la Comisión Vecinal Barrio Presidente Perón. ${ }^{49}$ En 1954 se constituyeron las denominadas "asociaciones vecinales" y obraron como un modelo asociativo a ser imitado por los vecinos de otros barrios. La pionera del nuevo tipo fue fundada al sur de la ciudad, en Barrio Las Ferias (3/10/1954), luego, hacia el norte de la ciudad, fue la Comisión Vecinal Barrio Santa Teodora (28/8/1955) y hacia el noroeste la Asociación Bajada de Arena (30-10-1955). ${ }^{50}$ Así comentaba el diario $\mathrm{La}$ Calle el nacimiento de la primera, dando por sentado que era una decisión autónoma de los vecinos sin injerencia municipal: "numerosas personas que allí se domicilian han resuelto organizar una reunión a los efectos de dejar constituida una comisión vecinal". ${ }^{51} \mathrm{El}$ mismo sentido puede inferirse de la nota que se envió al Concejo Deliberante poniendo en su conocimiento que "vecinos del Barrio Las Ferias reunidos en el domicilio del

se sentaron las bases teóricas de carácter estratégico y táctico para la formación del conductor político. Perón, Juan Domingo. Conducción politica. Disponible en: http:// www.generalperon.com/conduccion\%20politica.pdf [Consulta: 3 junio 2013].

49. AHM, Concejo Deliberante, Exp. № CXVI, Año 1953.

50. Las dos primeras existen en la actualidad, la tercera se disolvió a los dos años.

51. La Calle, Río Cuarto, 8/10/1954, p. 2.

72
Sr. Adolfo Dufourc han resuelto constituir una Asociación Vecinal". ${ }^{52}$ Con posterioridad se enviaría notas similares al ministro de gobierno de la provincia, al senador, al intendente, al jefe de policía comunicándoles la formación de la entidad y los fines perseguidos. El mismo tenor de perfil autónomo lo registró el acta constitutiva de la tercera vecinal mencionada, al decir: "los vecinos del Bajada de Arena y adyacentes han decidido formar una asociación vecinal". ${ }^{53}$

Estos datos permitirían inferir el carácter espontáneo del movimiento. Sin embargo, en las entrevistas por nosotros realizadas quedó claro, ante una pregunta explícita, que la ordenanza municipal abrió las puertas para legitimar la movilización del vecindario. ${ }^{54}$

Este asociacionismo compartía con el primer fomentismo varios aspectos: la institucionalidad, la idea de fomentar el progreso del barrio en todos sus aspectos, la difusión de actividades y la postura no partidista. No obstante, aparecían otros novedosos:la franja socio-económica de vecinos se modificó y la generación de argentinos predominó sobre los extranjeros. Así, en las asambleas vecinales, comisiones directivas y como socios participaron comerciantes, empleados, pequeños empresarios (fabricantes, curtiembres) y profesionales (abogados), también algunos civiles que servían en las fuerzas armadas. La mayoría de los vecinos habían nacido en la ciudad, aunque otros

52. AHM, Concejo Deliberante, Exp. No CXC, Año 1954.

53. AHM, Archivo "Vecinales Extinguidas", Carpeta 6, folio 216 .

54. En palabras de Francisco Odierno: "En función de esa Ordenanza de Castagno, que estaba antes del nacimiento de las vecinales, decidimos constituirnos en una Asociación Vecinal". 
provenían de las provincias vecinas..$^{55}$ Otro elemento novedoso fue la intención de formar una cooperativa de consumo, una sociedad mutual y estrechar vínculos con otras dirigencias barriales, hecho que se consumó al crearse en 1957 la Federación de Asociaciones Vecinales, integrada por los presidentes de cada una de las comisiones y sin la presencia de ningún miembro del poder municipal. ${ }^{56}$

Un tercer aspecto a destacar fue la inclusión de la mujer. En efecto, la primera asociación vecinal buscó y logró como práctica inédita atraer al género en su condición de vecina y propietaria. Integrada por dieciocho vecinos, incorporó entre ellos una mujer -Corina Baigorria- en calidad de secretaria de la comisión de prensa y cultura. Luego, se organizó una subcomisión de damas (12/3/1955) con el objeto de organizar las actividades sociales de la entidad. Esa comisión estaba presidida por la esposa de uno de los integrantes de la asociación, Olga B. de Ghiglione. Sus restantes miembros eran vecinas del lugar y esposas de otros miembros de la vecinal.

Un aspecto más a destacar es el énfasis puesto en demarcar la territorialidad de las nuevas organizaciones. Cada una de ellas explicitó los barrios que comprendía y la delimitación de las calles en los cuales quedaba comprendido su accionar.

Otro cambio de notar fue que una vez constituida la asociación, ya no hubo más registro de petitorios presentados a las autoridades por fuera de aquella, con lo cual quedaba de manifiesto no solo que se había

55. BASCONZUELO, Celia, La experiencia..., Op.Cit.

56. Archivo Histórico Municipal de Río Cuarto, Libro de actas de la Federación de Asociaciones Vecinales. erigido una nueva representación social, sino que además era reconocida y legitimada por el colectivo barrial como la única instancia habilitada para mediar ante el municipio.

Por último, ¿cómo se planteó la relación con el gobierno intendencial? ¿Hubo un proceso de peronización de estas identidades? De acuerdo con las expresiones de sus ex dirigentes no se habría registrado en Río Cuarto lo que vivieron las sociedades fomentistas de la provincia de Buenos Aires. En esta ciudad intermedia, los líderes vecinales insistieron, por el contrario, que pudieron desarrollar sus actividades con plena autonomía y fueron apoyados por el gobierno peronista local. ${ }^{57}$ Es más, con la anuencia del intendente, solicitaron -y obtuvieron- una entrevista con el gobernador de la provincia (Dr. Raúl Lucini) para gestionar el suministro de luz eléctrica para el barrio Las Ferias, entregándole un petitorio firmado por doscientos cuarenta y cinco vecinos; como respuesta obtuvieron el compromiso del mandatario de concretar el pedido a través de la dirección provincial de energía eléctrica.

En síntesis, así como el Estado peronista buscaba controlar, organizar y encauzar, el Estado municipal advirtió las ventajas de admitir ese activismo social, no politizado, que acudía a las oficinas del intendente y era

57. En palabras de Carlos Ghiglione: "Cuando se hizo la asociación, lo primero que hicimos fue visitar al Sr. Intendente que era entonces Natalio J. Castagno, peronista. Nos recibió con alegría y expresó que algo se había impuesto respecto de la existencia de Comisiones. Nosotros expusimos que la nuestra era espontáneo que hacíamos en función por derechos ciudadanos, valiéndonos de lo expresado por la Constitución. E1 intendente se dispuso con toda cordialidad a tener abierta la intendencia y estar dispuesto a colaborar con todo buen ánimo. Con el intendente Castagno y con el gobernador no tuvimos ninguna clase de problemas". 
portador de un discurso deferente y no se imponía como fuerza política vecinal sino “representativa de los vecinos”. ¿Por qué iban a ser contenidos? ¿Cómo impedir una dinámica de la sociedad civil que deparaba más ventajas que costos al gobierno municipal? Esos vecinos solidarizados y movilizados simplemente parecían identificar nudos problemáticos en los barrios y sugerían las respuestas. Al parecer, el peronismo local actúo con claro pragmatismo frente a las asociaciones vecinales.

\section{El final de la competencia}

En mayo de 1955 el conflicto del gobierno con la iglesia católica se hizo manifiesto como parte de una trama que anunciaba el momento más álgido para el peronismo. Meses después sobrevino el golpe militar ejecutado por la denominada revolución libertadora (16/9/1955). Entre uno y otro momento, las UB fueron interpeladas. En los primeros días de setiembre recibieron una comunicación del Consejo Superior que implicaba para todos los afiliados del Partido ratificar su afiliación en cada UB. Se argumentaba que era para adecuar las directivas partidarias a la acción política del Movimiento y reajustar los cuadros partidarios. Casi todas las UB barriales de Río Cuarto redactaron telegramas a las autoridades del Partido ratificando la lealtad a Perón y al movimiento. ${ }^{58} \mathrm{La}$ afiliación y la militancia de base, concebidas como un eslabón celular, debían mostrar en la hora crítica la fortaleza de su construcción territorial. Precisamente, en esas circunstancias hubo una movilización desde los barrios, impulsada por las UB y por el Partido, hacia el centro de la ciudad y así

58. La Calle, Río Cuarto, 7/9/1955, p. 3; 15/6/1955, p. 3; 1/9/1955, p. 2 "comenzó a reunirse público convergente de todos los barrios de la ciudad que manifestaron constantemente su adhesión al primer magistrado de la Nación expresando sus deseos de que continúe dirigiendo los destinos del país".

El golpe sobrevino y hacia la sociedad civil se desplegó un proyecto de "desperonización" que implicaba, ante todo, desmantelar la identidad política peronista con todos sus contenidos particulares, instituciones, organizaciones y representaciones. Entonces, ese campo de acción vecinal dejaba márgenes libres para la acción ciudadana. No es casual entonces que el proceso asociativo creciera de modo geométrico en los años sucesivos, en cada barrio que se urbanizaba y consolidaba poblacionalmente.

En síntesis, queda claro que durante los últimos años peronistas la participación social y comunitaria que tenía como lugar de manifestación los barrios de la ciudad, no se vio entorpecida, aunque sí controlada. Las comisiones de vecinos fueron reguladas y articuladas al gobierno municipal mediante la figura política del Delegado Municipal. No obstante, ello no impidió el despegue de un movimiento vecinal, tal como se ha señalado.

\section{A modo de conclusión}

Este artículo abordó las prácticas de participación localizadas en los barrios de la ciudad de Río Cuarto, en la modalidad social y comunitaria representada en este caso por las asociaciones de vecinos, $y$ en la modalidad política a cargo de las UB. 
Desde el punto de vista histórico, se ha realizado un aporte al conocimiento de la relación que el peronismo estableció con las sociabilidades fomentistas, lo cual ha sido parcialmente explorado hasta el momento. En tanto las tesis prevalecientes indicarían que hubo un fenómeno de peronización que alcanzó al asociativismo de base, el caso estudiado permitiría matizar este supuesto. Es cierto para el caso de algunas comisiones actuantes en los barrios, particularmente en Alberdi. De todos modos, los vecinos continuaron peticionando de manera informal, tal como lo venían haciendo, o bien canalizaron sus propuestas a través de las comisiones existentes y cuando se organizaron nuevas asociaciones en 1954, el relato obtenido a partir de las entrevistas permite inferir que gestionaron en articulación con la intendencia -un intendente electo por el vecindario-, pero sin presumirse de ello una lesión a su autonomía o proceso de cooptación. Por su parte, las UB operaron en distintos campos, arrebatándole al fomentismo la acción cultural y social y sentando un adoctrinamiento que iba a competir con las otras identidades (religiosa, vecinal, deportiva) que integraban la trama barrial y disputaban su colectivo de referencia. Otra diferencia a su favor fue que los restantes partidos políticos no conseguían mantener estables -tampoco lo habrían intentado- los subcomités barriales que se activaban en tiempos electorales, tanto para instancias legislativas como municipales.

Entonces, la modalidad de participación que cada actor forjó en el vecindario, con algunas prácticas similares, con otras diferenciadas, confluía en la capacidad para apropiarse del espacio barrial y crear territorialidad cuyos alcances eran diferenciales. Así, mientras el primer y segundo fomentismo buscó delimitar su radio de acción, el cual no podía prolongarse más allá de ciertos límites cartográficos las UB, si bien celulares, estaban articuladas a una estrategia mayor de posicionamiento territorial que las excedía y a la vez las contenía.

El peronismo en los barrios de Río Cuarto buscó y logró controlar el campo asociativo, indujo las inquietudes vecinales bajo el formato con el cual iba a dialogar, porque la arquitectura peronista fiel al principio de organización y unanimidad política legitimaba esa y otras prácticas, pero no demasiado como para frenar una dinámica de la sociedad civil que comenzó a desenrollar aún con el peronismo en pie; luego, tras el proceso de desperonización ya no encontró escollos invencibles. Nuevamente las fronteras entre el Estado y la sociedad civil, que el peronismo había contribuido a desdibujar, parecían visibilizarse.
Recibido: $25 / 07 / 2013$ Aceptado: 06/03/2014 